\title{
Smart Billing System Using RFID
}

\section{Prof. M. P. Shinde, Himanshu Dhore, Vivek Parab, Malhar Badame}

MIT Polytechnic, Kothrud, Pune, Maharashtra, India

\begin{abstract}
Article Info

Volume 7, Issue 3

Page Number: 473-476

Publication Issue :

May-June-2021

\section{Article History}

Accepted : 25 May 2021

Published : 31 May 2021

In this century technology had played the important role in our life. We have seen technology in each and every field due to which works becomes easy and fast as well. We can see the technology ever where we go which makes human work more efficient and fast, whether it be billing in the mall, etc. Technology should reduce the time required for the job to be done and accurate outputs are expected every time, keeping this in mind we have developed "Smart Billing System Using RFID" to make billing efficient to the user. In our project we have used technologies like RFID, etc. After taking items customer will go to counter and give biller he will scan and check quality and give to customer.

Keywords: RFID, ICSP, MFRC, NXP, 12C, SPI, UART
\end{abstract}

\section{INTRODUCTION}

Today, we get everything in malls like food items, utensils or electronic items. People mainly refer malls to shop due to availability of each and every resource in one place. People choose weekend to visit the malls due to their hectic and busy lifestyle and on other days they have to manage their work hours so they prefer to weekends. They mainly shop for the whole week or month making their shopping list big. Which led to the lot of rush in the mall creating a long queue for the billing and takes lot of time as the number of product purchased is more. So we have proposed "Smart Billing System Using RFID" with various technologies which help in fast billing and efficient shopping. Our project helps the user to shop efficient as they have to scans the product to the RFID reader attach to the trolley and helps to transfer the data to main computer. This system is interactive and reliable. With the help of this system shopping is made easy and reliable to the user and needs less manpower and reduces the long queue.

\section{HARDWARE OVERVIEW}

\section{Arduino UNO}

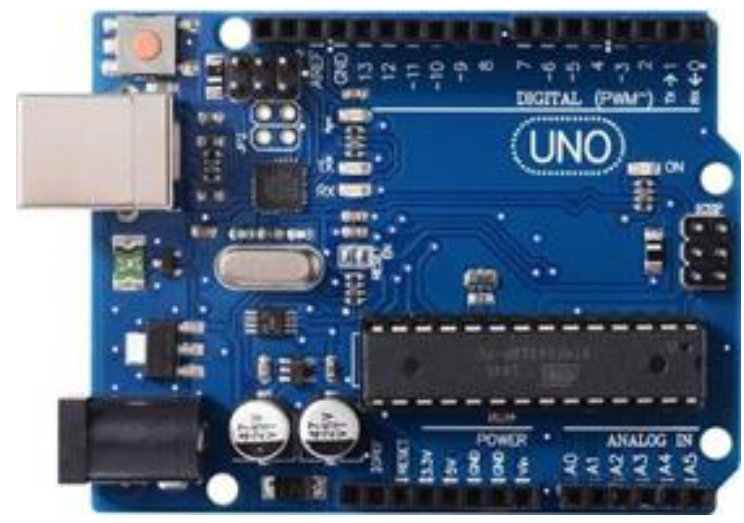

Arduino Uno is a microcontroller board based on the ATmeaga328P. it has 14 digital input/output pins, 6analog inputs, a $16 \mathrm{MHz}$ ceramic resonator, a USB connection, a power jack, an ICSP header and a reset 
button. It contains everything needed to support the microcontroller; simply connect it to a computer with USB cable or power it with a AC-to-DC adapter or battery to get started.

\section{RFID RC-522}

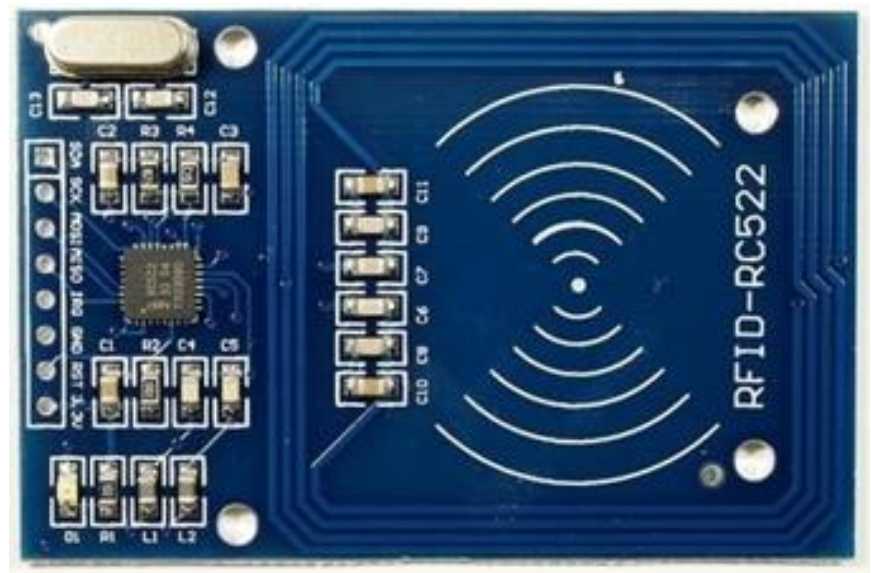

The RC 522 is a 13.56 megahertz RF ID module that is based on MFRC 522 Controller from NXP semiconductors full stop the model can support 12C, SPI and UART and normally $\mathrm{H}$ ship with are you for the card and key fob. It is commonly used in attendance systems and other person/object identification applications.

\section{RFID Card}

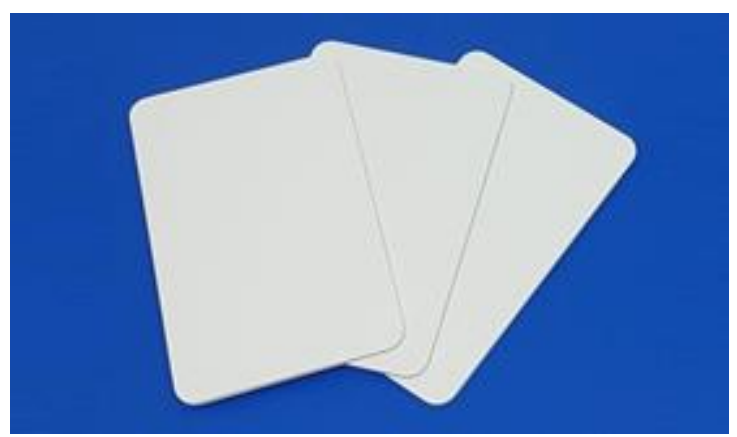

Radio frequency identification RF ID is the use of radio waves to read and capture information stored on the tag attached to an object. A tag can be read from up to several feet away and does not need to be within direct line-of-sight of the reader to be tracked.

\section{SOFTWARE OVERVIEW}

1) Visual Studio Code (2019)
Version- 16.9.5

2) Microsoft My SQL Server(2018) Version- 18.9.1

3) Arduino IDE

Version- 1.8.15

\section{LITERATURE SURVEY}

Deepthi M4, Shiva Prasad KM5 Department of Computer Science \& Engineering, RYMEC, Ballari The super shops are the places where people go to buy their daily using products and also pay for that. So the need to calculate the number of products sold and generation of bill for the customer. When people go for the shopping in a shop, we have to select the right product. After that, it's a hectic to stand in line for billing purpose. Hence, we are going to propose the "Smart Shopping Cart System" that will save the track of products which are purchased and calculate the bill using RFID reader and Transmitter and Receiver. The system will also provide suggestions for products to buy based on user purchase history from a centralized system. In "Smart Shopping Cart System" every product in Mart will be attached with RFID tag, and every cart will be having RFID Reader, LCD display and Transmitter and receiver attached to.

\section{PRODUCT PRESPECTIVE}

The products in the shop will have RFID tag attached to it. RFID reader is attached to the trolley to scan RFID is used to transfer the data to main computer.

\section{SYSTEM ARCHITECTURE}

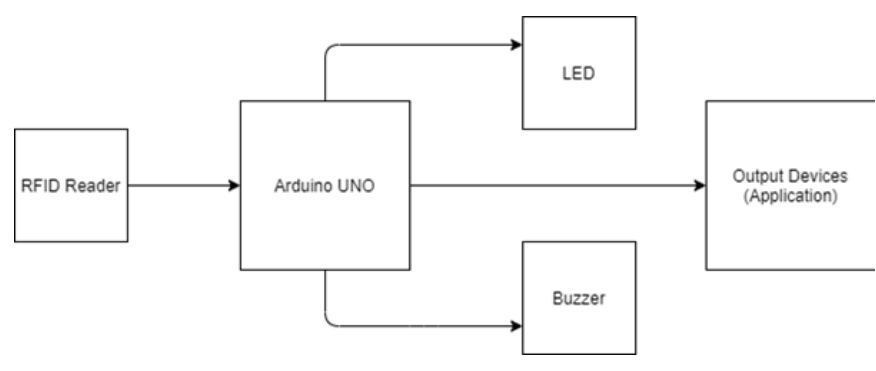

VII. MODULES DEVELOPED 
Login Module:

Login module will help to access the application with having right id and password assigned to the worker to that Desktop.

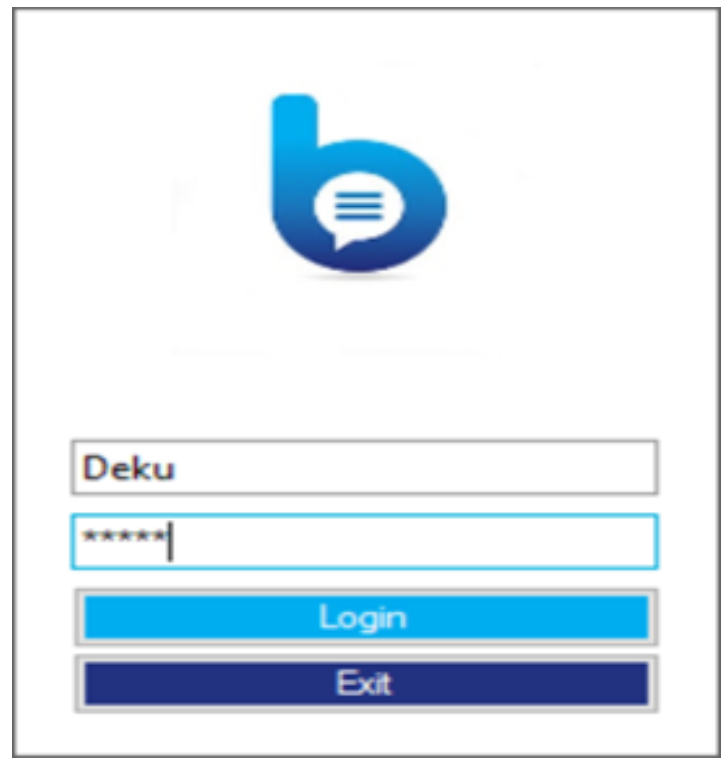

Connectivity Module:

Connection of Rfid and application is established over here.

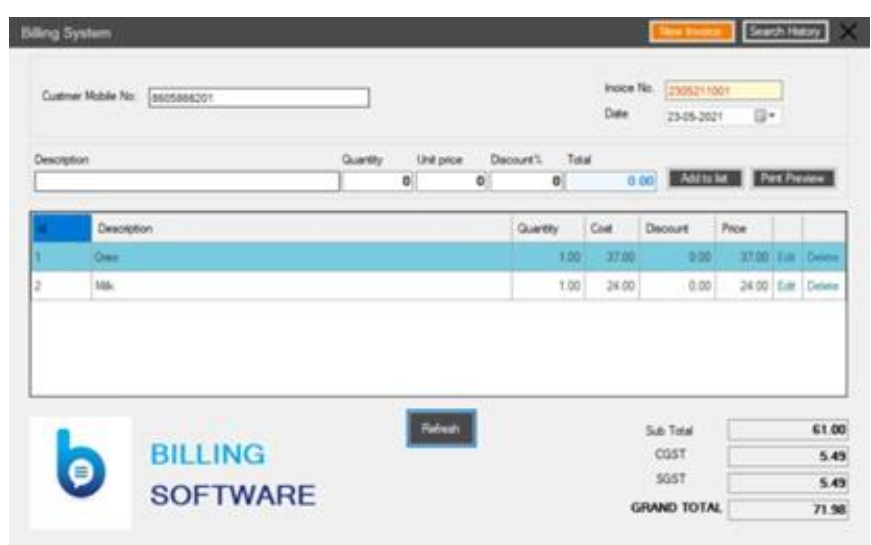

Search Module:

This module helps to search the bill.

1. Searching of bill can be done by entering billing date.

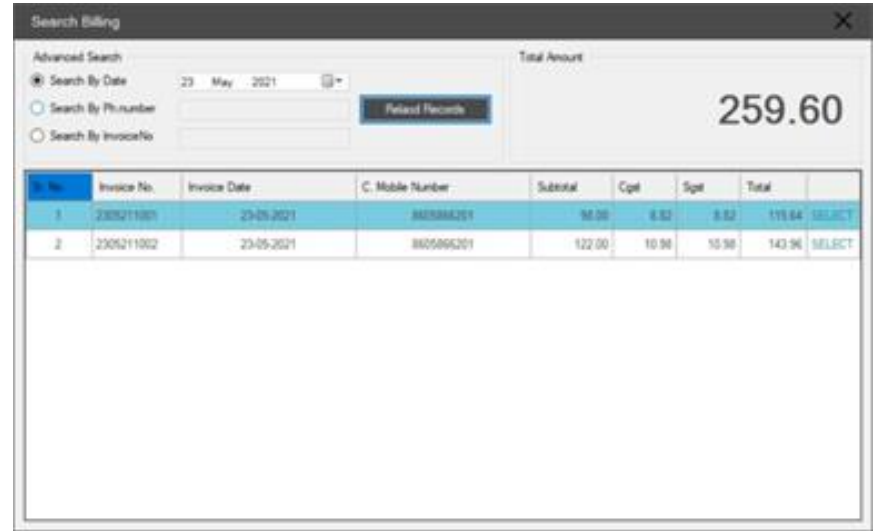

2. Searching of bill can be done by entering customer mobile number.

\begin{tabular}{|c|c|c|c|c|c|c|c|c|}
\hline \multicolumn{9}{|c|}{ Shorch Bang } \\
\hline \multicolumn{4}{|c|}{ Nereces Sement. } & \multirow{4}{*}{\multicolumn{5}{|c|}{$10,52,001.04$}} \\
\hline \multirow{3}{*}{\multicolumn{2}{|c|}{ 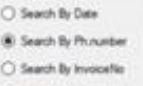 }} & \multirow{3}{*}{ 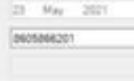 } & & & & & & \\
\hline & & & \multirow[t]{2}{*}{ 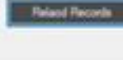 } & & & & & \\
\hline & & & & & & & & \\
\hline 18 & meat: & nowates & Crostherer & senst & $\cos$ & $s \infty$ & $\operatorname{Tax}$ & \\
\hline t & senereat & ceani & mersount & $\tan x$ & 180 & $n 0$ & $\operatorname{sex} x$ & ment \\
\hline 2 & OS6021000 & onstar & mocososes & 000000 & $\sin \infty$ & $\sin \infty$ & $x>000$ & मакет \\
\hline 3 & cosernosi & $\sec 221$ & messucen & 5000000 & 50000 & 300000 & 1000000 & saker \\
\hline 4 & cosestives & moson: & messowest & 0000000 & $\operatorname{sen} \alpha$ & $\sin \infty \theta$ & 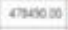 & श्रार्टा \\
\hline 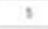 & mexisios & Ston mat & monoweri & $2 x \times s e x$ & zansos & nexse & $\cos \infty$ & saver \\
\hline 1 & 10s:100 & ตen: & mosous! & $\infty x$ & 584 & 573 & sseat & WIET \\
\hline$\Rightarrow$ & isesentioe & $1305 \times 201$ & mosowont & $w \infty$ & 285 & us & 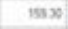 & sanct \\
\hline 1 & 15 Sert1000 & $7905: 202$ & mosecusen & $1+\infty$ & 56 & 50 & $\pi n$ & guxet \\
\hline , & 15xation & $15052 m$ & wosmown: & $m x$. & $5 \omega$ & net & 2854 & makct \\
\hline 10 & 158021004 & $1805 x=24$ & newowost & $=\infty$ & 32 & 18 & $\mathrm{man}$ & must \\
\hline "1 & sostions & $1505 x 201$ & messwont & 200 & 20 & 211 & ew & seber \\
\hline
\end{tabular}

3. Searching of bill can be done by entering invoice number.

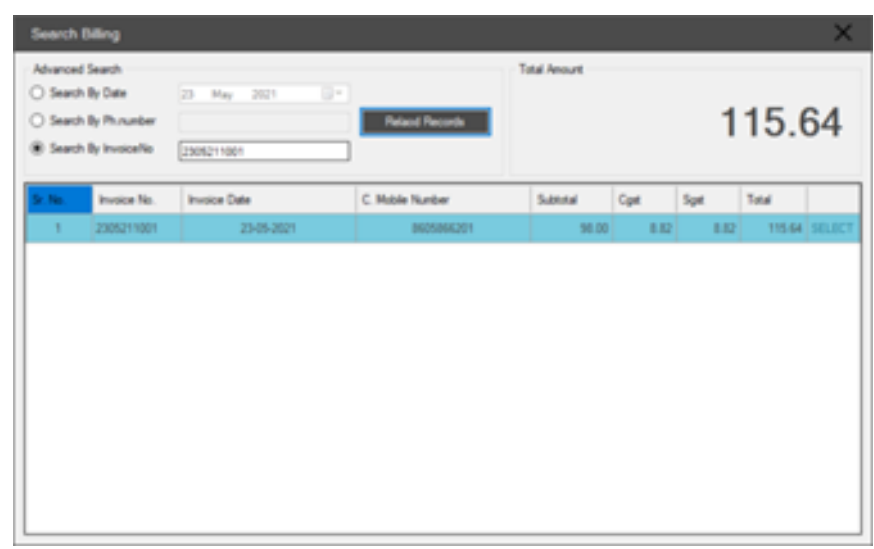

Print module:

This module helps to show the preview of the bill to print and also to print the bill. 


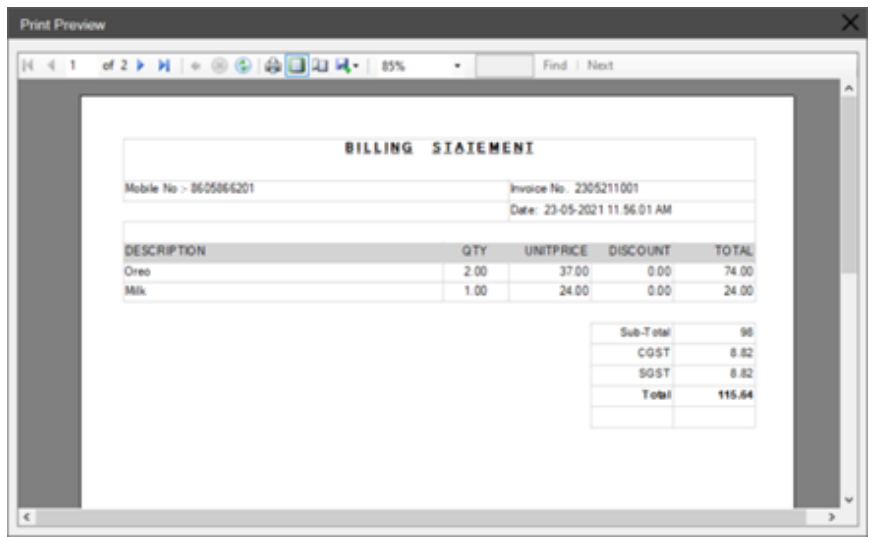

Payment Method:

In this method user can pay the bill. (Cash payment only)

Hardware Assembly:

Here we are connecting Arduino Uno with RFIDRC522, Buzzer \& LED.

When user scans ID, the data will be send to database \& entry of their product will get display on billing software \& hence buzzer \& LED's will indicate successful entry.

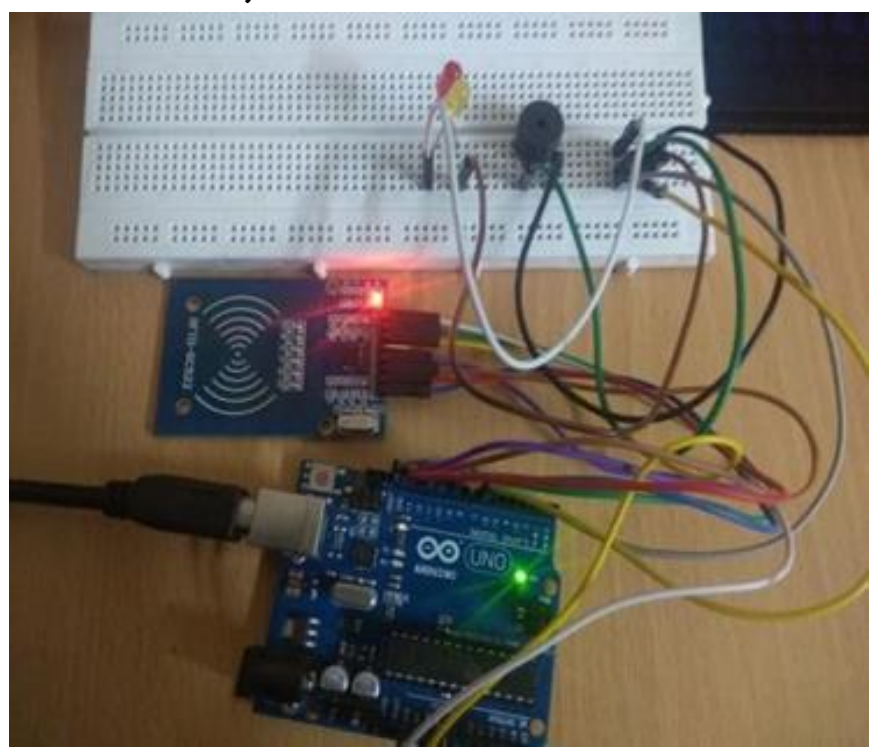

\section{FUTURE SCOPE}

In future we can add various payment options such as Debit/Credit card, Google pay, etc. We can also send bill through message to save the paper.

\section{CONCLUSION}

When the item is scanned by the customer the RFID reader reads the tag and immediately item details will be shown on the LCD screen and the data will be stored on the server. The developed product is easy to use, cost-effective and does not need any special training. This system based on RFID technology is efficient, and it shows the promising performance.

\section{REFERENCES}

[1]. Prakruthi K, Sowmya B, Kiran B, and Manjunatha K N. (2017). "DESIGN AND DEVELOPMENT OF LOW COST SMART BILLING SYSTEM." International Journal of Research - Granthaalayah, 5(4) RACEEE, 141146.

[2]. https://doi.org/10.5281/zenodo.580 640.

[3]. Mr.P. Chandrasekar and Ms.T. Sangeetha "Smart Shopping Cart with Automatic Billing System through RFID and Transmitter and Receiver ",IEEE,2014

[4]. CONTROL THEORY \& INFORMATICS ISN 2224 - 5774 ( PRINT ) ISSN 2225 - 0492 (ONLINE), VOLI NO 1, 2011 RFID Based System SAURABH KUMAR SULTANIA SOURAV JAISWAL , PRATEEK JAIN

\section{Cite this article as :}

Prof. M. P. Shinde, Himanshu Dhore, Vivek Parab, Malhar Badame, "Smart Billing System Using RFID", International Journal of Scientific Research in Computer Science, Engineering and Information Technology (IJSRCSEIT), ISSN : 2456-3307, Volume 7 Issue 3, pp. 473-476, May-June 2021. Available at doi : https://doi.org/10.32628/CSEIT217397 Journal URL : https://ijsrcseit.com/CSEIT217397 